\title{
Evidence for antifouling biocides as one of the limiting factors for the recovery of macrophyte communities in lakes of Schleswig-Holstein
}

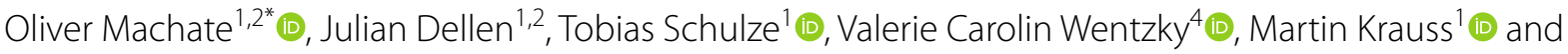
Werner Brack ${ }^{1,3}$ (1)

\begin{abstract}
Background: The European Water Framework Directive (WFD) has been implemented to achieve a good ecological status in European water bodies requiring macrophyte community assessment as one of the biological quality elements (BQEs). While in several lakes in Schleswig-Holstein (Germany) different BQEs improved within recent years, no recovery of macrophyte communities in some lakes could be achieved, despite the reduction of nutrient input and eutrophication. Due to the fact that no impairment of phytoplankton could be observed, toxic stress due to sediment contamination was hypothesized as a possible limiting factor of macrophyte community recovery.

Results: Sediment toxicity was investigated by performing an extensive chemical screening of sediment contamination and a risk assessment based on toxic unit (TU) summation, using equilibrium water concentrations and algal toxicity as surrogates for lacking data on macrophyte toxicity. Possible indirect risks via toxic pressure on grazer were assessed via TUs based on crustaceans. The study revealed algal TUs of more than one order of magnitude below chronic toxicity thresholds in lakes with high and good status of the macrophyte community and increasing concentrations and frequency of exceedance of toxicity thresholds for lakes with moderate-to-bad status. The antifouling biocides irgarol and diuron were identified as major risk drivers. In addition, PAHs and glyphosate could not be ruled out to contribute to toxic pressure on macrophytes. Despite exceedance of toxicity thresholds for crustaceans, no connection of the ecological status of the macrophyte communities with toxic risks to grazers could be observed.

Conclusions: Our study suggests that in a multiple pressure situation the toxic pressure created due to the contamination of sediments with antifouling biocides is one of the limiting factors for the recovery of macrophyte communities in impaired lakes of Schleswig-Holstein. This finding is in agreement with a Europe-wide survey on almost 47,000 sites suggesting that no good ecological status can be observed at sites with contamination exceeding toxicity thresholds. Similar to the survey, our study indicates additional stressors preventing the achievement of a good quality status of the lake ecosystems.
\end{abstract}

Keyword: Organic micropollutants, Ecological quality, Lakes, Macrophytes, Sediment toxicity, Biocides

*Correspondence: oliver.machate@ufz.de

1 Department of Effect Directed Analysis, Helmholtz Centre for Environmental Research-UFZ, Permoserstrasse 15, 04318 Leipzig,

Germany

Full list of author information is available at the end of the article

\section{Background}

Freshwater lakes are valuable ecosystems and provide crucial ecosystem services including maintenance of biodiversity, carbon sequestration and hydrological buffering, sediment and nutrient retention and processing, 
supporting fishery and human recreation and as a source of drinking water [1]. Thus, the European Water Framework Directive (WFD) has been implemented in order to maintain and achieve a good ecological status in all European lakes and rivers. The directive addresses four biological quality elements (BQE) including fish, invertebrates, phytoplankton and macrophytes [2]. For the state of Schleswig-Holstein (SH) (Germany), long-term monitoring data on the ecological status of the many lakes are available [3]. These data indicate that the BQE phytoplankton improved considerably over the recent years, while the same does not apply for the macrophyte communities. Abundance, as well as species composition of the underwater flora remains impoverished in many lakes, even if nutrient input and eutrophication have been reduced to a degree that should allow for a return to healthy macrophyte communities. While eutrophication of the lake water, leading to reduced light conditions due to increased algae growth, and the accumulation of phosphorus in sediments are well known to affect the state of macrophyte communities [4-6], also other factors including toxic stress need to be considered [7].

In addition to long-term impaired lakes, also one of the lakes with the best preserved macrophyte community of SH (Lake Suhrer), and entire Germany, experienced a local macrophyte extinction in the year 2017 [7]. Due to the proximity of the lake to agricultural fields and high precipitation rates in 2017, pesticide runoff has been suggested as a possible driver of this decline. Nutrients and other typical factors that may limit the accomplishment of a good status of the macrophyte communities could be excluded. Since phytoplankton communities seemed to be unaffected, the pollution of the water phase was not expected to be the dominant exposure pathway. In contrast to phytoplankton, macrophytes grow in direct contact to sediments and may take up sediment-borne pollutants via their roots $[8,9]$. Based on the observations in Lake Suhrer and the unexplained long-term impaired lakes within $\mathrm{SH}$, we hypothesized that sediment contamination might be one of the drivers that limit the recovery of the macrophyte communities and planned our study accordingly. Toxic chemicals have previously been identified as drivers of risks to aquatic ecosystems [10], while Posthuma et al. [11] demonstrated mixtures of chemicals as a factor limiting the potential to reach a good ecological status in surface waters on a European scale. However, it is often challenging to directly link adverse effects on ecosystem integrity to the presence of toxic pollution since ecological degradation is often the result of multiple stressors simultaneously affecting organisms [12-14].

In the current study, we investigated whether sediment contamination with pesticides, biocides and other chemicals may be a driver for the degradation of macrophyte communities in several lakes in $\mathrm{SH}$. The sediments of eight lakes, covering different quality states with respect to the macrophyte community, were subjected to an extensive target screening of herbicides, biocides and other plant protection products (PPP) complemented with some markers for recent and legacy sediment contamination such as polycyclic aromatic hydrocarbons (PAHs), polychlorinated biphenyls (PCBs) and chlorinated pesticides. This follows the assumption of a direct impact of phytotoxins on the macrophyte community. In addition, potential indirect toxic effects of chemicals to crustaceans as proxies for grazers, which have been reported to support regime shifts from macrophyte to phytoplankton dominated ecosystems [15], were assessed by including current-use insecticides in our analysis. Due to a lack of toxicity data for macrophytes, assessments were based on algal toxicity data. Considering their exposure pathways, longer generation times and thus lower recover rates, this indicates that macrophytes might be even more sensitive to many chemicals than algae [16]. Assuming equilibrium-partitioning with sediment total organic carbon (TOC), sediment concentrations were used to estimate freely dissolved equilibrium concentrations and calculate pollutant mixture effects according to the model of concentration addition using cumulative toxic units (TU) [17]. The herbicide glyphosate, which is one possible cause of macrophyte degradation, does not primarily bind to organic carbon. Since for this compound no straight forward methods to estimate freely dissolved concentrations exist, glyphosate was considered using dry weight-based concentrations.

\section{Material and methods}

\section{Sampling sites and sampling}

The sediments of eight lakes located in the state of $\mathrm{SH}$ with an ecological status of macrophytes ranging from bad to high and a habitat quality and a status of phytoplankton that is expected to allow for a healthy macrophyte community, were investigated (Fig. 1; Table 1). The lakes differ greatly in size, catchment area and water retention time. All lakes feature extensive agricultural production close to their shorelines. Some lakes are intensively used for recreational activities (Lake Diek, Lake Selenter and Lake Brahm) or border to urban areas (Lake Diek and Lake Trammer).

In each lake sediment samples were taken at several sites close to the shore at a water depth of $\sim 1.5 \mathrm{~m}$. In total 32 sites were sampled within the period from 20 to 24th May 2019, the time after spring application of pesticides. Upper sediment layers, with a thickness of 5-10 cm were sampled (Additional file 1: Supporting information), using a Van Veen grab sampler (stainlesssteel; height $1000 \mathrm{~mm}$, area $330 \times 300 \mathrm{~mm}$; maximum 


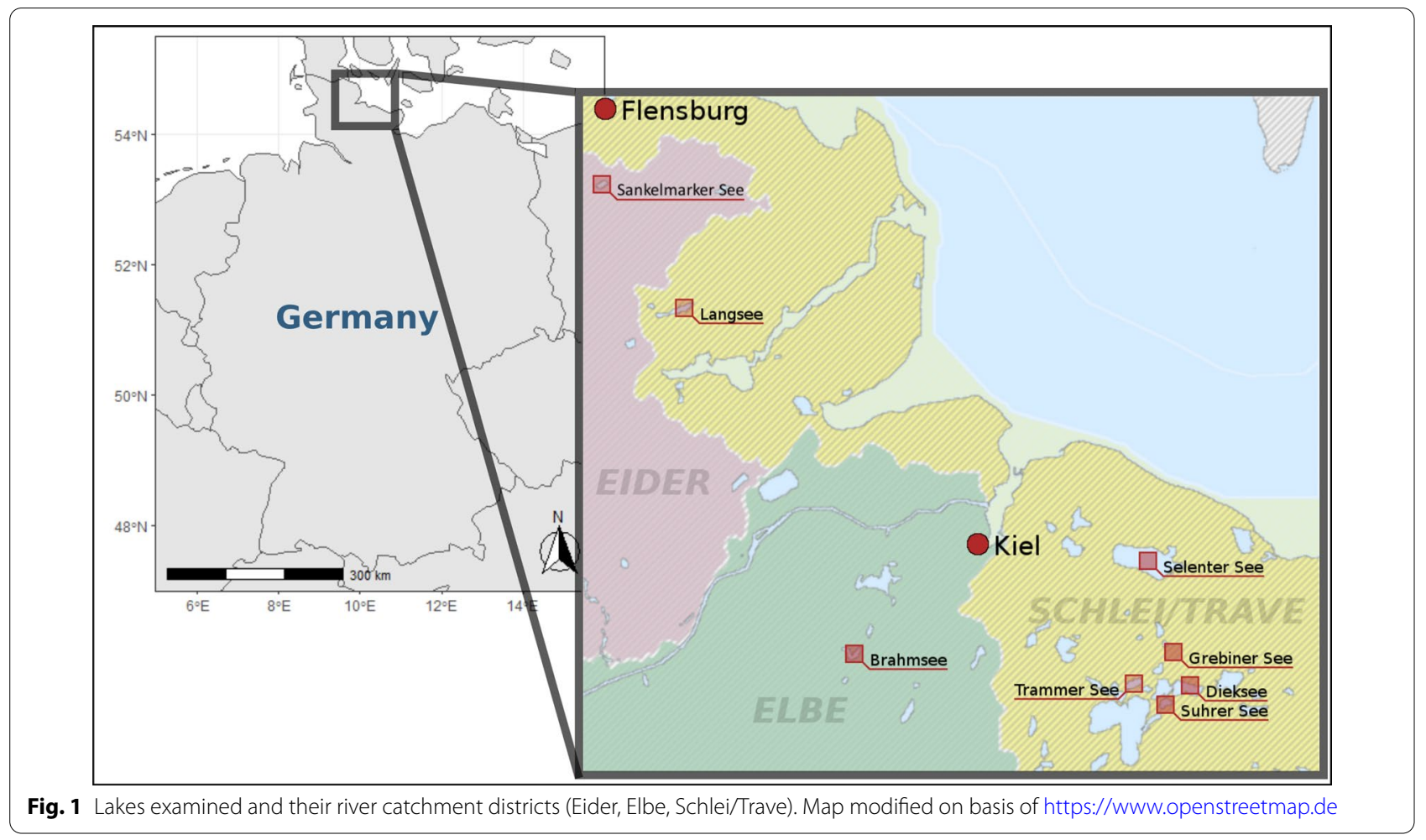

Table 1 Investigated lakes, their ecological states and most important variables describing their dimensions

\begin{tabular}{|c|c|c|c|c|c|}
\hline Lake & Macrophyte state $^{a}$ & Phytoplankton state $^{a}$ & Surface area $\left(\mathrm{km}^{2}\right)$ & Catchment area $\left(\mathrm{km}^{2}\right)$ & $\begin{array}{l}\text { Water } \\
\text { residence } \\
\text { time (a) }\end{array}$ \\
\hline Lake Brahm & 3 & 3 & 1.1 & 58.9 & 0.3 \\
\hline Lake Diek & 4 & 2 & 3.8 & 165.6 & 1.0 \\
\hline Lake Grebiner & 3 & - & 0.3 & 1.0 & 7.7 \\
\hline Lake Lang & 5 & 2 & 1.4 & 31.7 & 0.8 \\
\hline Lake Sankelmarker & 5 & 2 & 0.6 & 18.8 & 0.6 \\
\hline Lake Selenter & 1 & 2 & 21.2 & 60.0 & 15.4 \\
\hline Lake Suhrer & 2 & 2 & 1.4 & 4.1 & 8.8 \\
\hline Lake Trammer & 4 & 2 & 1.6 & 4.2 & 13.8 \\
\hline
\end{tabular}

a Ranking according to WFD ranging from 1 (very good) to 5 (bad); data were kindly provided by the State Office for Agriculture, Environment and Rural Areas (LLUR)

sampling capacity $5 \mathrm{~kg}$ ). At each sampling site three individual samples were taken and pooled in equal parts to a composite sample using a stainless-steel spoon. All samples were stored on ice in a solvent washed, sealable aluminium bowl and deep-frozen at the same day at $-20{ }^{\circ} \mathrm{C}$ until further processing.

\section{Sediment extraction and chemical analysis}

To obtain the organic-rich fine fraction (grain sizes $<63 \mu \mathrm{m}$ ) for pollutant extraction, the whole, freezedried sediment sample was sieved through DIN ISO
3310-1 standardized stainless-steel test sieves on a KS1 vibratory shaker (Retsch). The TOC content was measured in duplicates using a Vario EL Cube elemental analyser. Assuming that organic carbon is the major sorbent for organic chemicals in sediments, sediment aliquots containing $100 \mathrm{mg}$ of TOC were extracted and cleanedup using a modified method developed by Massei et al. [18]. Using the TOC content as a basis also helps to keep matrix effects in the mass spectrometer on a similar level in different samples safeguarding the comparability of analyses. More details on the TOC measurement, 
pressurized liquid extraction (PLE) and subsequent flashchromatography can be found in Additional file 1: SI 2 .

Subsequently a target screening was performed for 218 compounds using liquid and gas chromatography-highresolution mass spectrometry (LC-HRMS and GCHRMS). Compounds known for their phytotoxicity were analysed-including agricultural herbicides and other current-use pesticides; biocides used in antifouling paints (e.g. diuron and irgarol) and household products (e.g. triclosan and triclocarban); but also insecticides as potential indirect cause of macrophyte community degradation and PAHs, PCBs and other legacy substances as markers for legacy contamination. The more hydrophobic analytes, consisting of 67 substances (Additional file 2: (AF), sheet 1), were measured using a GC with QExactive MS system (Thermo) equipped with Thermal Desorption Unit (TDU-2; Gerstel, Mülheim, Germany) and a cooled injection system (CIS; Gerstel). The remaining $151 \mathrm{com}-$ pounds (Additional file 2: sheet 2) were analysed using an UltiMate 3000 LC system (Thermo) coupled to Q Exactive Plus MS (Thermo) with a heated electrospray ionization source. More detailed information on chemical analysis and the equipment used can be found in Additional file 1: SI 4.

A different analytical approach was used for the frequently used herbicide glyphosate, as it exhibits a high polarity and is not compatible to the used screening techniques. Based on a method used by Muskus et al. [19] glyphosate was extracted from the sediment by using a sodium borate buffer at a $\mathrm{pH}$ of 9 . The extracts were purified by solid-phase extraction on an HR-X cartridge prior to derivatization with 9-fluorenylmethyl chloroformate (FMOC-Cl) and analysed using an ABSciex Q-TRAP $6500 \mathrm{LC}-\mathrm{MS} / \mathrm{MS}$ in negative ion mode. More details can be found in Additional file 1: SI 3.

\section{Data evaluation and quality control}

Compounds were quantified by method-matched internal calibration using 9 (GC) and 40 (LC) isotope-labelled compounds (Additional file 1: SI 5). The calibration standards were prepared at 12 levels, ranging from 0.2 to $1000 \mathrm{ng} / \mathrm{mL}$, by spiking $5 \mathrm{~mL}$ of ethyl acetate/acetone $(1: 1 \mathrm{~V} / \mathrm{V})$ with the respective amounts of target analytes and consecutively subjecting them to the same clean-up procedure as the sediment samples. Internal standards were added to both, the standards and the sediment samples. Target substances were allocated to their respective internal standards based on similarity in retention time. Method detection limits (MDLs) were determined based on the lowest measurable standard (Additional file 2: sheet 3).

The raw data files generated during LC-HRMS analysis were converted to mzML data using the ProteoWizard
MSConvert tool (v. 3.0.18265) [20]. Subsequently, peak detection, sample alignment and target compound annotation were performed in MZmine (V 2.40.1) [21] as detailed elsewhere [22]. An in-house R package (MZquant v0.6.1) was used to perform blank correction, calibration and finally quantification of the annotated target compounds. Briefly, for blank peak elimination, a blank intensity threshold was calculated according to,

$$
I_{i, t, \text { blank }}=\mu\left(I_{i, \text { blank }}\right)+2 \cdot \sigma\left(I_{i, \text { blank }}\right),
$$

where $I_{i, t \text {,blank }}$ is the intensity threshold, $\mu\left(I_{i, \text { blank }}\right)$ is the average intensity and $\sigma\left(I_{i \text {,blank }}\right)$ is the standard deviation of each peak $i$ in the blank samples. All peaks with

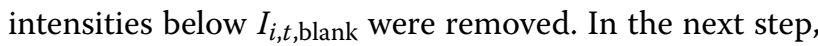
the nested internal standard peak with the nearest retention time was assigned and the peak intensity of the target compound was divided by the peak intensity of the internal standard to gain the relative intensity ratio. Calibration models were fitted by a generalized additive model with integrated smoothness estimation (GAM) using the $\mathrm{R}$ package mcgv (v. 1.8-31) [23]. The GAM model was selected to account for linear and nonlinear regression fits without need of manual model selection. For improvement of the calibration models, the supporting points of the regression were trimmed to a range between the minimum and maximum intensities in the samples. The minimum number of supporting points for each model was four. Finally, the GAM models were applied to quantify the target compounds. For quantification of GC-HRMS-detected compounds, the software TraceFinderTM 4.1 (Thermo Scientific) was used for further evaluation. No blank correction was performed. R Version 3.6.2 (2019-12-12; "Dark and Stormy Night") [24] was used in combination with the "ggplot2" software package version 3.2.1 [25] to visualize the data.

\section{Risk assessment to macrophytes and grazers}

The risk of chemical pollution towards macrophyte health was assessed using TUs $[26,27]$. The TUs were calculated based on equilibrium water concentrations that were derived from the organic carbon-normalized sediment concentrations ( $\left.c_{i, \text { organic carbon }}\right)$ via organic carbon-water equilibrium partition coefficients $\left(K_{\mathrm{OC}}\right)$ according to Eq. (2):

$$
c_{i, \text { water }}=\frac{c_{i, \text { organic carbon }}}{K_{\mathrm{OC}}} .
$$

For PAHs and PCBs, $K_{\mathrm{OC}}$ values were used that have been derived in larger field studies and are deemed most reliable $[28,29]$. For the remaining substances polyparameter linear free energy relationships (pp-LFERs) were applied to model their partitioning coefficients [30]. 
All required compound descriptors were acquired from the LSER database of the Helmholtz-Environmental Research Centre [31]. Where possible, measured descriptors have been used. If these were not available, the buildin prediction software of the LSER database was used to derive missing compound descriptors. An overview of the used $K_{\mathrm{OC}}$ values can be found in Additional file 2: sheet 5 .

Cumulative TUs were calculated according to Eq. (3):

$$
\sum \mathrm{TU}=\sum_{\mathrm{i}=1}^{\mathrm{n}} \frac{\mathrm{C}_{\mathrm{i}} \text { water }}{\mathrm{EC}_{\mathrm{x}_{\mathrm{i}}}},
$$

where $c_{i \text {,water }}$ is the equilibrium water concentration of the analyte $i$ and $\mathrm{EC}_{x_{i}}$ is its effect concentration (EC) at level $x$. Since ecotoxicological data for macrophytes are scarce, TUs calculations were based on EC-values for algal toxicity as a proxy. Effect levels from no observable effect levels (NOEL), lowest effect levels (LOEL), and $\mathrm{EC}_{10}$ up to $\mathrm{EC}_{90}$ were retrieved from the US EPA ECOTOX Knowledgebase (release version 09 December 2019) for exposure times of up to $120 \mathrm{~h}$. The no observable effect concentration (NOEC) and lowest observable effect concentration (LOEC) data were not considered because these endpoints are static and not derived by modelling. The 0.05 quantiles $\left(Q_{0.05}\right)$ of the obtained data for each compound entry were calculated according to Busch et al. [32]. This approach considers a worstcase scenario to be protective. If no measured entry was available (applies for app. $45 \%$ and $52 \%$ of EC-values for algae and crustacean, respectively), the $\mathrm{EC}_{50}$-value for green algae was estimated by using baseline ECOSAR 1.0 $[33,34]$ type model in ChemProp 6.3 [35]. The baseline ECOSAR-type QSAR was used due to the low coverage of the compounds under consideration without measured toxicity data by group-specific QSAR. More details on the method can be found in Additional file 1: SI 6 and in Schulz et al. [36]. Similar to algae, also for crustacean reported EC-values were obtained from the US EPA ECOTOX Knowledgebase or predicted via baseline ECOSAR 1.0 type. For assessment of the likelihood of adverse effects, including direct phytotoxicity and indirect effects via toxicity to grazing macroinvertebrates, $\Sigma$ TUs were compared with thresholds for acute $(0.1$ TUs for both organisms) and chronic (0.02 TUs for algae; $0.001 \mathrm{TUs}$ for crustacean) toxic effects as defined and used previously $[10,37]$.

Unlike for the rest of the substances, the adsorption of glyphosate mainly occurs via ion exchange. Therefore, using the $K_{\mathrm{OC}}$ to calculate equilibrium water concentrations would be misleading. Amorphous $\mathrm{Fe} / \mathrm{Al}$ oxides play an important role for glyphosate sorption and have been used in soil adsorption models [38, 39]. In order to be able to utilize the soil adsorption models to reliably predicted equilibrium water concentrations we determined the content of amorphous $\mathrm{Fe} / \mathrm{Al}$ oxides as described by Schwertmann et al. [40]. Since Fe/Al oxide contents in the investigated sediments $\left(0.04-4 \mathrm{~g} \mathrm{Al}_{\mathrm{Ox}} / \mathrm{kg}\right.$ and $0.2-$ $48 \mathrm{~g} \mathrm{Fe}_{\mathrm{Ox}} / \mathrm{kg}$ ) were clearly out of the range covered by these models, a derivation of reliable equilibrium water concentrations for glyphosate and the calculation of TUs was not possible and tentative conclusions on possible risks will rely on sediment concentrations only.

\section{Results}

\section{Sediment concentrations}

Out of the 219 chemicals analysed, 62 were detected at least in the sediment of one site. The detected chemicals consist of seven herbicides, 12 other pesticides (four insecticides and eight fungicides), five biocides used in antifouling paints, seven other biocidal substances, 20 PAHs and 11 legacy compounds (seven PCBs and four legacy pesticides) (Additional file 2: sheet 3 and 4). The largest number of chemicals could be detected at site 5 of Lake Lang (41 substances) and the smallest at site 5 of Lake Trammer (13 substances). PAHs are ubiquitously occurring in the investigated lake sediments. With concentrations ranging from 1.3 to $409 \mu \mathrm{g} / \mathrm{g}$ TOC (avg. 52 $\mu \mathrm{g} / \mathrm{g}$ TOC), they accounted for the largest fraction of the measured compounds in the sediments. Benzo(k) fluoranthene, benzo(a)anthracene, benzo(a)pyrene and indeno(1,2,3-cd)pyrene occur as the PAHs with the highest concentrations (Fig. 2). Lake Lang was most polluted with PAHs, followed by Lake Diek and Trammer, all having a poor or bad macrophyte state. Lower PAH levels could be found in Lake Suhrer and Lake Grebiner with a high and moderate macrophyte state, respectively. Also other persistent pollutants could be detected frequently. Chlorinated legacy PPPs and PCBs were found in $75 \%$ and $65 \%$ of all samples, respectively. Lake Suhrer, Brahm, Lang and Sankelmarker were most contaminated with legacy compounds while in Lake Selenter, Grebiner, Trammer and Diek the levels of these compounds were low. Total PCB concentrations in the lake sediments range from 0.004 to $0.6 \mu \mathrm{g} / \mathrm{g}$ TOC (avg. $0.08 \mu \mathrm{g} / \mathrm{g}$ TOC) with PCBs 138, 149, 153 and 180 detected most frequently and PCB 138 and 153 exhibiting greatest concentrations. Lake-wide PCB pollution could be observed in Lake Brahm, Lang, Suhrer and Sankelmarker with local maxima at site 4 of Lake Brahm $(0.6 \mu \mathrm{g} / \mathrm{g}$ TOC $)$ and Lake Suhrer $(0.5 \mu \mathrm{g} / \mathrm{g}$ TOC). Legacy PPP concentrations ranged from 2 to $20.5 \mathrm{ng} / \mathrm{g}$ TOC (avg. $4.9 \mathrm{ng} / \mathrm{g}$ TOC) with 4,4'-DDE and 4,4'-DDD being detected most frequently and at highest concentrations. Site 6 of Lake Suhrer shows the highest chlorinated legacy PPPs level with $20.5 \mathrm{ng} / \mathrm{g}$ TOC. 


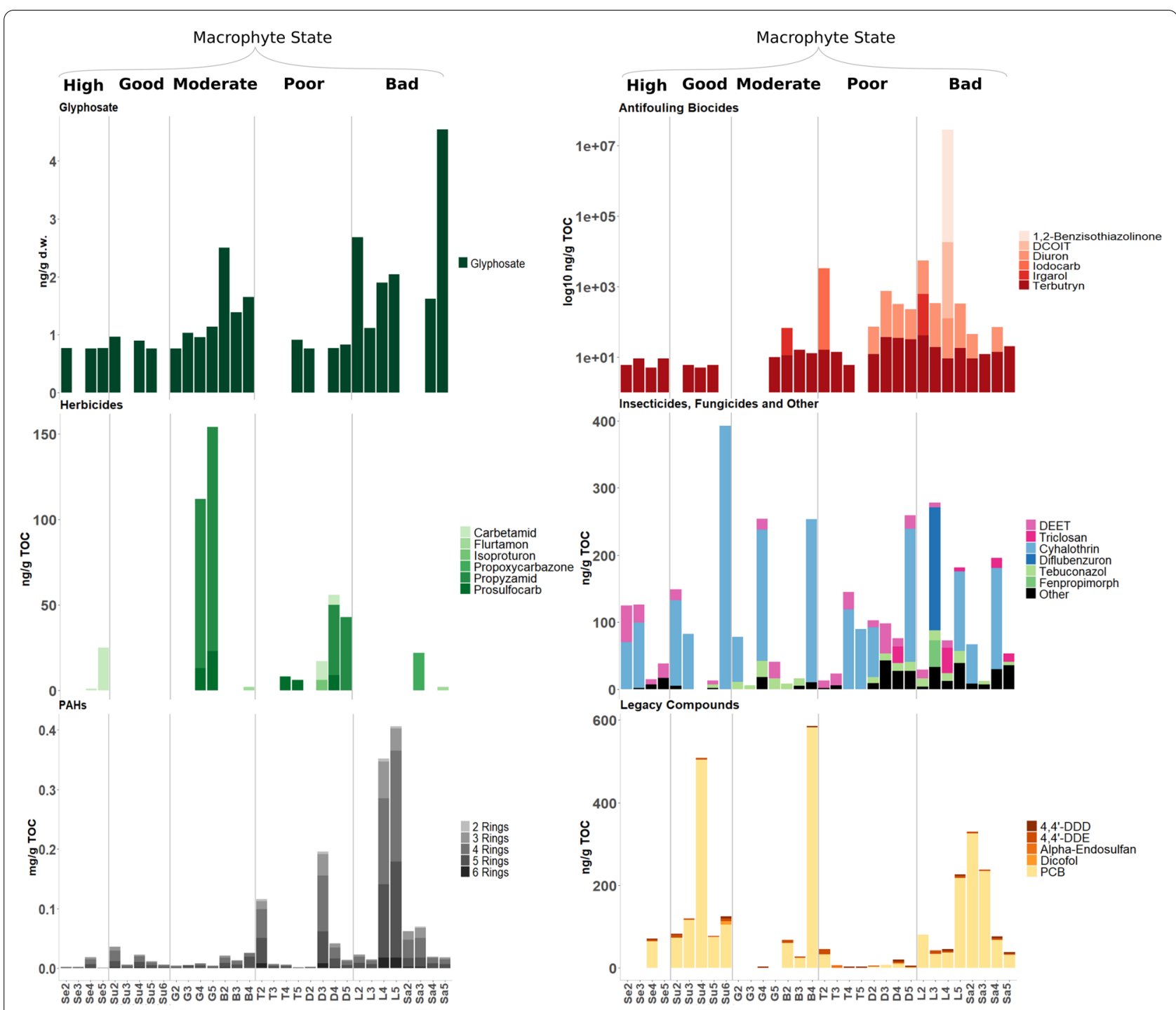

Fig. 2 Barplots of detected sediment concentrations. Pollutants are grouped according to their different uses. All compounds stated in ng/g TOC, except from glyphosate which is stated in $\mathrm{ng} / \mathrm{g}$ dry weight. At the sampling points Sa2 and Sa3 glyphosate could not be measured

Current use herbicides and other pesticides (currently registered on the German market) were detected in most samples and ranged from 0.6 to $39.8 \mathrm{ng} / \mathrm{g}$ TOC. For herbicides the magnitude of the contamination varied by two orders of magnitude between different lakes. Concentrations were highest in Lake Grebiner, which is characterized by a moderate macrophyte state and lowest in Lake Selenter and Lake Suhrer, having a high and good macrophyte state. The herbicide glyphosate was detected in $77 \%$ of all samples and was thus the most frequently detected agricultural herbicide in lake sediments. At the sites with high and good macrophyte states in Lake Selenter and Lake Suhrer glyphosate concentrations remained below $1 \mathrm{ng} / \mathrm{g} \mathrm{dw}$, while for the lakes with moderate-to-bad status often higher concentrations were observed with a maximum of $4.5 \mathrm{ng} / \mathrm{g} \mathrm{dw}$ in Lake Sankelmarker. The highest insecticide concentrations were found for cyhalothrin and diflubenzuron (0.4 and $0.2 \mu \mathrm{g} / \mathrm{g}$ TOC). Particularly cyhalothrin is detectable at many sites (app. $50 \%$ of sites) at similarly high concentrations independent of the macrophyte state.

Biocides could be detected in $88 \%$ of all samples. Their concentrations ranged from 0.005 to $1.8 \mu \mathrm{g} / \mathrm{g}$ TOC (avg. $0.09 \mu \mathrm{g} / \mathrm{g}$ TOC). Biocides used in antifouling paints were mainly found in lakes of poor or bad macrophyte state. This includes Lake Diek, Lake Sankelmarker and Lake Lang. It is also Lake Lang that revealed the highest biocide concentration with $1.5 \mu \mathrm{g} / \mathrm{g}$ TOC 
1,2-benzisothiazolinone at site 4 . The antifouling biocides irgarol, diuron and terbutryn were detected in $\sim 6,30$ and $80 \%$ of the samples. Their concentrations range from 6 to $15 \mathrm{ng} / \mathrm{g}$ TOC for irgarol, 5 to $20 \mathrm{ng} / \mathrm{g}$ TOC for diuron and 6 to $45 \mathrm{ng} / \mathrm{g}$ TOC for terbutryn. The insect repellent DEET was detected in $60 \%$ of the samples at concentrations of 6 to $41 \mathrm{ng} / \mathrm{g}$ TOC.

\section{Assessment of potential risk for macrophytes}

Following the main assumption on direct effects of phytotoxic chemicals on macrophytes, but also considering possible indirect effects on grazers of phytoplankton and phytobenthos, additive risks, expressed as $\sum$ TUs, were calculated based on equilibrium water concentrations (Additional File 2: sheet 5) and effect concentrations to algae and daphnia (Additional File 2: sheet 6 and 7). The $\sum$ TUs based on algal toxicity exceeded thresholds for chronic phytotoxic effects at $22 \%$ of all sampling points (Fig. 3a). All of these exceedances were observed in lakes of moderate to poor macrophyte state. The sites with a good or high status of the macrophyte community exhibit $\sum$ TUs of $1 \times 10^{-3}$ to $2 \times 10^{-3} \sum$ TUs (average: $1.7 \times 10^{-3} \sum$ TUs) and thus one order of magnitude below the assumed chronic toxicity threshold of 0.02 $\sum$ TUs. At sites in lakes with a moderate status $\sum$ TUs ranged from $5 \times 10^{-4}$ to $0.03 \sum$ TUs (average $6 \times 10^{-3}$ $\sum$ TUs) and exceeded 0.02 TUs at one site (Lake Brahm, site 2). In lakes of a poor or bad macrophyte state $\sum \mathrm{TUs}$ ranged from $4 \times 10^{-4}$ to 0.04 (average $0.01 \sum \mathrm{TUs}$ ) and $6 \times 10^{-3}$ to 0.09 (average $0.03 \sum \mathrm{TUs}$ ), respectively. The

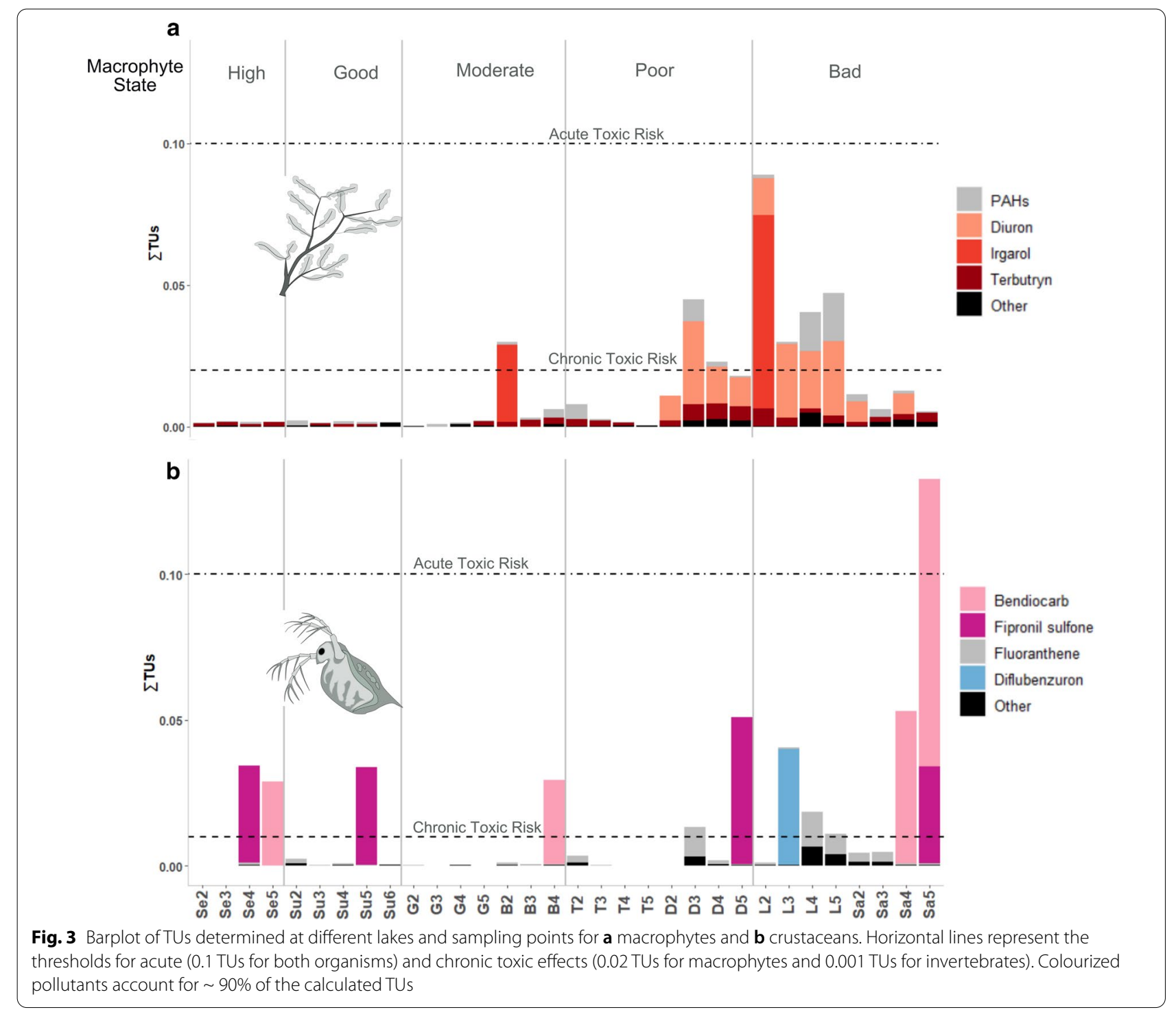


chronic toxicity threshold of $0.02 \Sigma T$ Us was exceeded at two sites in a lake of poor macrophyte state (both in Lake Diek) and four sites in a lake of bad macrophyte state (all in Lake Lang).

At those sites with $\sum$ TUs close to or above $0.02 \Sigma$ TUs, antifouling biocides used in paint coatings of facades, underwater structures and boats (irgarol, diuron and terbutryn) predominate the $\sum$ TUs. In two of the sites phytotoxicity is dominated by irgarol (B2 with $0.03 \mathrm{TU}$ and L2 with $0.07 \mathrm{TU}$ ), in Lakes Diek and Lang diuron is the phytotoxicity driver (up to $0.03 \mathrm{TUs}$ ). Terbutryn is adding minor contributions to many sites of up to $6 \times 10^{-3}$ TUs. PAHs have been identified as a second group of phytotoxicity drivers, with the sum of PAHs causing $4 \times 10^{-5}$ to $0.02 \Sigma$ TUs. Benzo(a)pyrene, perylene, benzo(k)fluoranthene and chrysene are the PAHs that contribute most to the toxic units. An exceedance of the chronic toxicity threshold due to PAHs occurs at two sites both in Lake Lang (site 4 and 5). The phytotoxicity-based $\Sigma$ TUs related to agricultural herbicides (except glyphosate) and other plant protection products considered here, are consistently very low and remain several orders of magnitude below the chronic toxicity threshold for algae. Same applies for legacy pesticides and PCBs.

For glyphosate no TU-based assessment based on equilibrium water concentration could be performed. Based on dry weight-based sediment concentrations, low glyphosate levels ( 0.76 to 1 ; avg. $0.5 \mathrm{ng} / \mathrm{g} \mathrm{dw}$ ) have been observed for lakes of good to high status of the macrophyte community, while lakes of moderate-to-bad macrophyte state exhibit concentrations of 0.8 to $4.5 \mathrm{ng} / \mathrm{g}$ $\mathrm{dw}$. It may be assumed that this may result also in higher equilibrium water concentrations of glyphosate and thus a greater likelihood of impact in lakes of moderate-tobad macrophyte state.

\section{Assessment of potential risk for grazers}

The $\sum$ TUs based on crustacean toxicity range from $6 \times 10^{-5}$ to 0.13 TUs (average: $0.01 \sum \mathrm{TU}$ ) with the highest $\sum$ TUs being observed at site 5 of Lake Sankelmarker (Fig. 3b). In lakes of good to moderate status of the macrophyte community, $\sum$ TUs between $5 \times 10^{-5}$ and 0.03 TUs (average: $8 \times 10^{-3} \sum$ TUs) can be observed. In case of a poor or bad macrophyte state $\sum$ TUs range from $8 \times 10^{-4}$ to 0.13 TUs (average: $0.02 \sum$ TUs). $\sum$ TUs exceed the threshold for chronic toxic effects of $1 \times 10^{-3}$ TUs at $56 \%$ of all sites. Exceedances occur in lakes of all macrophyte states. The insecticidal biocides bendiocarb and fipronil sulfone, a metabolite of fipronil, contribute most of the toxic units by causing 0.03 to $0.1 \mathrm{TUs}$ and 0.03 to 0.05 TUs, respectively. Although the insecticide cyhalothrin was detected frequently and revealed substantial sediment concentrations, it only contributes to a small extent to the calculated TUs. Reason for this is an EC that is one magnitude higher than the EC-values of bendiocarb and fipronil sulfone. This also holds true when comparing the EC-values used in the present study with the data provided in the IUPAC Pesticides Properties Database [41].

\section{Discussion}

\section{Biocide and PAH concentrations compared} to concentrations in other European sediments

Concentration data on the biocides irgarol, diuron and terbutryn in European lake sediments for comparison are rare. However, sediment data are available for European estuaries, including the rivers Danube, Elbe, Gironde, Po, Rhine, Scheldt and Tiber. While maximum concentrations of irgarol, diuron and terbutryn in our study were 15,20 and $45 \mathrm{ng} / \mathrm{g}$ TOC, respectively, the detected concentrations in estuary sediments range from 10 to $120 \mathrm{ng} / \mathrm{g}$ TOC for irgarol, 20 to $120 \mathrm{ng} / \mathrm{g}$ TOC for diuron and 20 to $130 \mathrm{ng} / \mathrm{g}$ TOC for terbutryn [42]. Thus, maximum sediment concentrations in the investigated lakes were in the lower range of major European estuaries, while maximum estuary sediment concentrations exceeded those in the sediments of the lakes under investigation by factors of $3-8$. Given the strong impact on estuary sediments from shipping traffic and from draining big parts of Europe including major urban, industrial and high intensity agricultural areas, these factors are astonishingly low. Thus, biocide contamination in some of the lakes with moderate-to-bad macrophyte state may be considered as substantial. Interestingly, diuron and irgarol were identified as the main drivers of toxic pressure on algae in the study on estuary sediments. The screening of dated sediment cores of Lake Lugano and Lake Greifensee in Switzerland indicated a strong increase of irgarol concentrations from 2004 until 2014 reaching $3 \mathrm{ng} / \mathrm{g}$ dry weight [43]. Terbutryn concentrations already peaked in the 1970 s to about $0.5 \mathrm{ng} / \mathrm{g}$ dry weight while no data on diuron were presented. Assuming typical TOC fractions of few percent, these concentrations are substantially higher than the sediment concentrations measured in the lakes of this study and underline the potential of biocides to accumulate in lake sediments. Unfortunately, no data on impacts of biocides in the Lake Greifensee on macrophytes are available.

The accumulation of PAHs in lake sediments is well investigated with data from all over the world [44]. PAH concentrations observed at most of the sites investigated in this study are in good agreement with those observed in comparable lake sediments. One example may be sediments of rural lakes of Spain [45] with PAH levels of 4 to $4286 \mathrm{ng} / \mathrm{g}$ of sediment. Some of the sites in lakes of poor to bad macrophyte status (Lake Sankelmarker, Lake Diek 
and Lake Trammer), however, exhibited higher pollution levels (up to 10,625 $\mathrm{ng} / \mathrm{g} \mathrm{dw}$ ). Similar concentrations have been observed in sediments of an urban lake in Bergen (Norway) [46]. In Lake Lang two sites even showed PAH levels similar to those of heavily industrialized regions (site 4 with $45,106 \mathrm{ng} / \mathrm{g} \mathrm{dw}$ and site 5 with $44,393 \mathrm{ng} / \mathrm{g}$ $\mathrm{dw}$ ) [44]. Furthermore, the sediments showed to be substantially contaminated with the insecticide cyhalothrin (59-393 ng/g TOC) when compared to the sediment of European estuaries, where the maximum measured concentration was $51 \mathrm{ng} / \mathrm{g}$ TOC [42].

\section{Toxic pressure of sediment contamination as a limiting factor for macrophyte communities}

The results obtained in this study support our initial hypothesis that sediment-borne phytotoxicity is one of the limiting factors preventing macrophyte communities to reach a good or high status. Sediments of all sites with good or high status are contaminated well below the level where chronic phytotoxicity can be expected. Sites with moderate, poor and bad status are characterized by increasing levels of phytotoxic contamination and $\Sigma T$ Us increasingly exceeding chronic phytotoxicity threshold levels. These findings are in perfect agreement with the observations of another study by Posthuma et al. [47] that unravelled the existence of a relationship between the ecological status and the prevailing toxic pressure for European rivers. The study considered almost 47,000 European sites and concluded: mixture toxic pressure is a significant limiting factor and no good or high ecological status can be reached at sites with substantial toxic pressure. Their conclusion is confirmed in our study that indicates phytotoxic pressure as one of the limiting factors of good macrophyte status. Particularly in Lake Lang, Lake Diek and Lake Brahm, we suggest the reduction of phytotoxic pollution as a necessary pre-condition for the recovery of the macrophyte communities. However, the data also indicate a multiple stress situation where phytotoxicity is one of the limiting factors while additional stressors, such as habitat degradation, eutrophication, changing fish and grazer populations or increasing temperatures $[7,48]$ but also other chemicals, which have not been in the focus of this studies are expected to play a role. Thus, attempts should be made to identify and mitigate these other stressors in order to achieve macrophyte recovery and a good ecological status.

The potential of glyphosate to adversely affect macrophyte communities is well established $[49,50]$. Therefore, additional toxic pressure due to glyphosate as a driver of macrophyte decline should not be excluded. Although no equilibrium water concentrations and thus TUs could be estimated, total sediment concentrations indicate a higher level of pollution with glyphosate in lakes of moderate-to-bad macrophyte status. This probably also results in a higher equilibrium water (and thus bioavailable) concentration.

In some of the lake sediments, substantial contamination with the insecticides bendiocarb, fipronil sulfone and diflubenzuron has been observed, causing an exceedance of thresholds for chronic and, in case of one site, even acute toxic risk. However, these exceedances do not show any correlation to the macrophyte status. Thus, an indirect effect of insecticide pollution as a driver of the decline of macrophyte communities by adversely affecting grazer communities is not very likely.

\section{Antifouling biocides as drivers of toxic pressure}

Antifouling biocides, including irgarol, diuron and terbutryn, and to a lesser extend also PAHs, were identified as drivers of toxicity, thus, potentially limiting the quality status of the macrophyte communities. Irgarol, diuron and terbutryn are photosystem II inhibitors and have been shown to cause detrimental effects on aquatic ecosystems [51, 52]. They are especially used as active substances in antifouling paints (AFPs). Irgarol was almost exclusively applied as antifouling booster biocide on submerged surfaces of boats, ships and aquatic structures and its approval in Germany for this purpose was withdrawn in 2016 [53]. The application of terbutryn and diuron is broader and also includes their use in emulsion paints applied on facades. Diuron and terbutryn can be leached from there into adjacent waterbodies via urban runoff and wastewater $[54,55]$. Since all lakes are situated in close proximity to settlements and the density of boat traffic in the investigated lakes is low, we hypothesize that facade runoff might be an important source of the antifouling biocides that limit the recovery of the macrophyte communities in the lakes with moderate, poor or bad macrophyte state. This hypothesis is supported by the findings of another study that identified diuron transported via rain sewer effluents into river water as main driver of algal toxicity [56].

\section{Plausibility of the suggested sediment toxicity to macrophytes}

It has been shown that macrophyte species composition and abundance can respond strongly to the prevailing environmental conditions $[57,58]$ and direct contact to contaminated sediments has been shown to be a relevant exposure pathway for aquatic macrophytes $[8,9]$. The major phytotoxicity drivers in our study, irgarol and diuron, are well known to accumulate in sediments [59] and macrophytes have been shown to exhibit a high sensitivity to the identified biocides. This holds true for example for Chara vulgaris with a NOEL of $0.5 \mathrm{ng} / \mathrm{L}$ for irgarol and $500 \mathrm{ng} / \mathrm{L}$ of diuron [60]. In a pond mesocosm study, 
Myriophyllum verticillatum was the macrophyte species most sensitive to irgarol with an $\mathrm{EC}_{10}$ of $60 \mathrm{ng} / \mathrm{L}$ after 150 days of exposure and exhibited high bioconcentration factors (BCF) of up to 10,560 L/kg [61]. Estimated maximum equilibrium water concentrations in our study were $6 \mathrm{ng} / \mathrm{L}$ for irgarol, $20 \mathrm{ng} / \mathrm{L}$ for terbutryn and $36 \mathrm{ng} / \mathrm{L}$ for diuron and thus were above (irgarol) or less than a factor of 50 below (diuron) than the NOEC- and $\mathrm{EC}_{10}$-values reported for macrophytes. These findings agree with the hypothesis that antifouling biocides may act as drivers of sediment toxicity and thereby, prohibit the recovery of a good macrophyte state in Lake Lang, Lake Diek and Lake Brahm. Sediment contact tests, for example with Myriophyllum species may be used to further confirm these findings [62, 63].

\section{Conclusion}

The current study provides evidence that the contamination of sediments with the biocides irgarol and diuron and with PAHs is one of the drivers of adverse effects on the macrophyte communities in lakes of $\mathrm{SH}$. This result is in agreement with the findings of a Europe-wide survey that contamination exceeding toxicity thresholds does not allow for the achievement of a good or high ecological status. Thus, preventing the use of biocides as antifouling agents in the lakes, as well as mitigating the input of urban runoff contaminated with biocides from façade and roof applications, is suggested as necessary, although probably not in all cases sufficient measures to improve the ecological status in the lakes under investigation. Due to higher concentrations of glyphosate in impacted lakes compared to those with good or high macrophyte state, the impact of glyphosate contamination from agricultural application should be excluded. However, a targeted investigation of bioavailable concentrations, macrophyte exposure and toxicity testing are required to finally conclude on the role of glyphosate for the observed degradation. The frequent exceedance of chronic toxicity thresholds suggests potential impacts on macroinvertebrate communities. However, no influence of potentially impaired crustacean communities (and thus reduced grazing pressure on the phytoplankton) on macrophyte communities could be shown.

Although there are evidences from literature that the direct contact of macrophytes to contaminated sediments is a relevant pathway of exposure, investigating the uptake of irgarol and diuron from sediments into plants would help to further fortify the findings of this study. The data achieved in this study also indicate that additional stressors should be considered in a multiple stress approach, since sediment contamination is a limiting factor only at some of the degraded sites.

\section{Abbreviations}

WFD: Water Framework Directive; BQE: Biological quality element; SH: Schleswig-Holstein; PPP: Plant protection product; PAH: Polycyclic aromatic hydrocarbon; PCB: Polychlorinated biphenyl; TOC: Total organic carbon; TU: Toxic unit; SI: Supporting information; PLE: Pressurized liquid extraction; LC-HRMS: Liquid chromatography-high-resolution mass spectrometry; GC-HRMS: Gas chromatography-high-resolution mass spectrometry; MDL: Method detection limit; $\mathrm{K}_{\mathrm{OC}}$ : Organic carbon-water equilibrium partitioning coefficient; pp-LFERs: Poly-parameter linear free energy relationship; EC: Effect concentration; NOEL: No observable effect level; LOEL: Lowest observable effect concentration; NOEC: No observed effect concentration; LOEC: Lowest observable effect concentration; $Q_{0.05}$ : 0.05 Quantiles; AFP: Antifouling paint; BCF: Bioconcentration factor.

\section{Supplementary Information}

The online version contains supplementary material available at https://doi. org/10.1186/s12302-021-00500-3.

Additional file 1: SI1. Supporting_Information_Machate (2021).

Additional file 2. Additional_Information_Machate (2021).

\section{Acknowledgements}

We thank Michael Herzog, Margit Petre, Aleksandra Piotrowska and Hubert Schupke for their help during the sampling campaign, sample preparation and analysis. Furthermore, we thank Dorothee Ohlwein, Andrea Hoff and Wolf von Tümpling from the Central Laboratory for Water Analytics \& Chemometrics of UFZ for conducting the Fe and Al analysis of the oxalate extracts. The Q Exactive Plus LC-HRMS and the Q Exactive GC used are part of the major infrastructure initiative CITEPro (Chemicals in the Terrestrial Environment Profiler) funded by the Helmholtz Association.

\section{Authors' contributions}

OM led the sampling campaign, analysed the GC data, compiled LC and GC data and drafted the manuscript. JD supported the sampling, performed the sample preparation and analysis of the LC data. WB coordinated and supervised the study. TS provided the toxicity data and guidance on their application. VW planned and supported the sampling campaign. MK conducted the glyphosate analysis and contributed to data analysis. All authors read and approved the final manuscript.

\section{Funding}

Open Access funding enabled and organized by Projekt DEAL. This study has been funded by the Ministry of Agriculture, Rural Areas and Environment (LLUR) in Schleswig-Holstein.

\section{Availability of data and materials}

The datasets supporting the conclusions of this article are included within the article and its additional file.

\section{Declarations}

Ethics approval and consent to participate

No reporting on any animal or human data or tissue is included within this manuscript. Following no approval or consent is required.

\section{Consent for publication}

The data have been published in consent with the Ministry of Agriculture, Rural Areas and Environment (LLUR) in Schleswig-Holstein.

\section{Competing interests}

The authors declare they have no competing interests.

\section{Author details}

${ }^{1}$ Department of Effect Directed Analysis, Helmholtz Centre for Environmental Research-UFZ, Permoserstrasse 15, 04318 Leipzig, Germany. ${ }^{2}$ Department of Biology, University of Leipzig, Johannisallee 21-23, 04103 Leipzig, Germany. ${ }^{3}$ Department of Evolutionary Ecology and Environmental Toxicology, 
Goethe University Frankfurt, Max-von-Laue-Strasse. 13, 60438 Frankfurt am Main, Germany. ${ }^{4}$ State Agency for Agriculture, Environment and Rural Areas Schleswig-Holstein (LLUR), Department for Lakes, Hamburger Chaussee 25, 24220 Flintbek, Germany.

\section{Received: 7 February 2021 Accepted: 22 April 2021} Published online: 06 May 2021

\section{References}

1. Sterner RW, Keeler B, Polasky S et al (2020) Ecosystem services of Earth's largest freshwater lakes. Ecosyst Serv 41:101046

2. European Commission (2000): EU Water Framework Directive (WFD). In, eur-lex.europa.eu.

3. Landesamt Für Landwirtschaft Umwelt Und Ländliche RäumeSchleswig Holstein (2014). In: Abteilung Gewässer DS (ed) Ökologische Zustandsbewertung der größeren Seen in Schleswig-Holstein nach EG-Wasserrahmenrichtlinie

4. Yang X-E, Wu X, Hao H-L et al (2008) Mechanisms and assessment of water eutrophication. J Zhejiang Univ Sci B 9:197-209

5. Paerl HW (2009) Controlling Eutrophication along the freshwater-marine continuum: dual nutrient ( $\mathrm{N}$ and $\mathrm{P}$ ) reductions are essential. Estuaries Coasts 32:593-601

6. Carr GM (1998) Macrophyte growth and sediment phosphorus and nitrogen in a Canadian prairie river. Freshw Biol 39:525-536

7. Krambeck C (2020) Ausfälle submerser Vegetation und Verdrängung von Characeen durch Angiosperme in einem mesotrophen See und mögliche Rolle von Herbizideinträgen. Deutsche Gesellschaft für Limnologie

8. Diepens NJ, Arts GHP, Focks A et al (2014) Uptake, translocation, and elimination in sediment-rooted macrophytes: a model-supported analysis of whole sediment test data. Environ Sci Technol 48:12344-12353

9. Turgut C (2005) Uptake and modeling of pesticides by roots and shoots of Parrotfeather (Myriophyllum aquaticum) (5 pp). Environ Sci Pollut Res Int 12:342-346

10. Malaj E, Von Der Ohe PC, Grote M et al (2014) Organic chemicals jeopardize the health of freshwater ecosystems on the continental scale. Proc Natl Acad Sci 111:9549-9554

11. Posthuma L, Zijp MC, De Zwart D et al (2020) Chemical pollution imposes limitations to the ecological status of European surface waters. Sci Rep 10:14825

12. Brazner JC, Danz NP, Trebitz AS et al (2007) Responsiveness of great lakes wetland indicators to human disturbances at multiple spatial scales: a multi-assemblage assessment. J Great Lakes Res 33(42-66):25

13. Tockner K, Pusch M, Borchardt D et al (2010) Multiple stressors in coupled river-floodplain ecosystems. Freshw Biol 55:135-151

14. Weitere M, Altenburger R, Anlanger C et al (2021) Disentangling multiple chemical and non-chemical stressors in a lotic ecosystem using a longitudinal approach. Sci Total Environ 769:144324

15. Sayer CD, Hoare DJ, Simpson GL et al (2006) TBT causes regime shift in shallow lakes. Environ Sci Technol 40:5269-5275

16. Arts G, Davies J, Dobbs M et al (2010) AMEG: the new SETAC advisory group on aquatic macrophyte ecotoxicology. Environ Sci Pollut Res $17: 820-823$

17. Sprague JB (1970) Measurement of pollutant toxicity to fish. II. Utilizing and applying bioassay results. Water Res 4:3-32

18. Massei R, Byers H, Beckers L-M et al (2018) A sediment extraction and cleanup method for wide-scope multitarget screening by liquid chromatography-high-resolution mass spectrometry. Anal Bioanal Chem 410:177-188

19. Muskus AM, Krauss M, Miltner A et al (2019) Effect of temperature, pH and total organic carbon variations on microbial turnover of $13 \mathrm{C} 315 \mathrm{~N}$ glyphosate in agricultural soil. Sci Total Environ 658:697-707

20. Chambers MC, Maclean B, Burke R et al (2012) A cross-platform toolkit for mass spectrometry and proteomics. Nat Biotechnol 30:918-920

21. Pluskal T, Castillo S, Villar-Briones A et al (2010) MZmine 2: modular framework for processing, visualizing, and analyzing mass spectrometry-based molecular profile data. BMC Bioinformat 11:395-395

22. Beckers L-M, Brack W, Dann JP et al (2020) Unraveling longitudinal pollution patterns of organic micropollutants in a river by non-target screening and cluster analysis. Sci Total Environ 727:138388
23. Wood S (2019): mgcv: Mixed GAM Computation Vehicle with Automatic Smoothness Estimation. R package version 1.8-31

24. R Core Team (2018): R: a language and environment for statistical computing

25. Wickham H (2016) ggplot2: elegant graphics for data analysis. Springer, New York

26. Ginebreda A, Kuzmanovic M, Guasch H et al (2014) Assessment of multichemical pollution in aquatic ecosystems using toxic units: compound prioritization, mixture characterization and relationships with biological descriptors. Sci Total Environ 468-469:715-723

27. Sprague JB, Ramsay BA (1965) Lethal levels of mixed copper-zinc solutions for juvenile salmon. J Fish Res Board Can 22:425-432

28. Hawthorne SB, Grabanski CB, Miller DJ (2006) Measured partitioning coefficients for parent and alkyl polycyclic aromatic hydrocarbons in 114 historically contaminated sediments: part 1. KOC values Environ Toxicol Chem 25:2901-2911

29. Hawthorne SB, Grabanski CB, Miller DJ et al (2011) Improving predictability of sediment-porewater partitioning models using trends observed with PCB-contaminated field sediments. Environ Sci Technol 45:7365-7371

30. Nguyen TH, Goss K-U, Ball WP (2005) Polyparameter linear free energy relationships for estimating the equilibrium partition of organic compounds between water and the natural organic matter in soils and sediments. Environ Sci Technol 39:913-924

31. Ulrich N, Endo S, Brown TN et al. (2017) UFZ-LSER database v 3.2 [Internet]

32. Busch W, Schmidt S, Kühne R et al (2016) Micropollutants in European rivers: a mode of action survey to support the development of effect-based tools for water monitoring. Environ Toxicol Chem 35:1887-1899

33. Mayo-Beana K, Nabholza JV, Meylanb WM et al. (2009) USER'S GUIDE for the ECOSAR Class Program-MS-Windows Version 1.00. In: U.S. Environmental Protection Agency

34. Nabholz Jv, Cash G, Meylan Wm et al. (1998) ECOSAR: a computer program for estimating the ecotoxicity of industrial chemicals based on structure activity relationships. In: U.S. Environmental Protection Agency

35. Ufz Department of Ecological Chemistry (2016) ChemProp 6.3. http:// www.ufz.de/ecochem/chemprop

36. Schulze T, Küster E, Schlichting R et al. (2020) Comparison of novel and current approaches for the target- and non-target screening, effectbased monitoring and prioritisation of river basin specific pollutants to improve future water quality monitoring. In: Liska I, Wagner F, Sengl M, Deutsch K, Slobodnik J, Paunovic M (eds) Joint danube survey 4 scientific report: a shared analysis of the Danube River. ICPDR, Vienna

37. Kandie FJ, Krauss M, Beckers L-M et al (2020) Occurrence and risk assessment of organic micropollutants in freshwater systems within the Lake Victoria South Basin, Kenya. Sci Total Environ 714:136748

38. Sidoli P, Baran N, Angulo-Jaramillo R (2016) Glyphosate and AMPA adsorption in soils: laboratory experiments and pedotransfer rules. Environ Sci Pollut Res 23:5733-5742

39. Gimsing AL, Borggaard OK, Bang M (2004) Influence of soil composition on adsorption of glyphosate and phosphate by contrasting Danish surface soils. Eur J Soil Sci 55:183-191

40. Schwertmann U (1964) Differenzierung der Eisenoxide des Bodens durch Extraktion mit Ammoniumoxalat-Loesung. Z Pflanzenernaehr Dueng Bodenk 105:194-202

41. Lewis KA, Tzilivakis J, Warner DJ et al (2016) An international database for pesticide risk assessments and management. Hum Ecol Risk Assess Int J 22:1050-1064

42. Massei R, Busch W, Wolschke H et al (2018) Screening of pesticide and biocide patterns as risk drivers in sediments of major European river mouths: ubiquitous or river basin-specific contamination? Environ Sci Technol 52:2251-2260

43. Chiaia-Hernandez AC, Krauss M, Hollender J (2013) Screening of lake sediments for emerging contaminants by liquid chromatography atmospheric pressure photoionization and electrospray ionization coupled to high resolution mass spectrometry. Environ Sci Technol 47:976-986

44. Du J, Jing C (2018) Anthropogenic PAHs in lake sediments: a literature review (2002-2018). Environ Sci Process Impacts 20:1649-1666

45. Hijosa-Valsero M, Bécares E, Fernández-Aláez C et al (2016) Chemical pollution in inland shallow lakes in the Mediterranean region (NW Spain): PAHs, insecticides and herbicides in water and sediments. Sci Total Environ $544: 797-810$ 
46. Andersson M, Klug M, Eggen O et al (2013) Polycyclic aromatic hydrocarbons (PAHs) in sediments from lake Lille Lungegardsvannet in Bergen, western Norway; appraising pollution sources from the urban history. Sci Total Environ 470-471C:1160-1172

47. Posthuma L, Zijp MC, De Zwart D et al. (2020) Chemical pollution imposes limitations to the ecological status of European surface waters. Sci Rep 10

48. Posthuma L, Dyer SD, De Zwart D et al (2016) Eco-epidemiology of aquatic ecosystems: separating chemicals from multiple stressors. Sci Total Environ 573:1303-1319

49. Mudge JF, Houlahan JE (2019) Wetland macrophyte community response to and recovery from direct application of glyphosate-based herbicides. Ecotox Environ Safe 183:109475

50. Sesin V, Davy CM, Stevens KJ et al (2020) Glyphosate toxicity to native nontarget macrophytes following three different routes of incidental exposure. Integr Environ Assess Manage 17:597-613

51. Price ARG, Readman JW (2013) Booster biocide antifoulants: is history repeating itself. In: Late lessons from early warnings: science, precaution, innovation. Eur Environ Agency 265-278

52. European Environment Agency (2002) Late lessons from early warnings: the precautionary principle 1896-2000. In: Environmental issue report No. 22/2001. pp. 135-148

53. European Commission (2016) DURCHFÜHRUNGSBESCHLUSS (EU) 2016/107 DER KOMMISSION vom 27. Januar 2016 zur Nichtgenehmigung von Cybutryn als altem Wirkstoff zur Verwendung in Biozidprodukten der Produktart 21 In, Amtsblatt der Europäischen Union

54. Burkhardt M, Zuleeg S, Roger V et al. (2011) Biocides in facades runoff and storm water of urban areas

55. Bollmann U, Vollertsen J, Carmeliet J et al (2014) Dynamics of biocide emissions from buildings in a suburban stormwater catchment-concentrations, mass loads and emission processes. Water Res 56:66-76
56. Beckers L-M, Busch W, Krauss M et al (2018) Characterization and risk assessment of seasonal and weather dynamics in organic pollutant mixtures from discharge of a separate sewer system. Water Res 135:122-133

57. Szoszkiewicz K, Ciecierska H, Kolada A et al (2014) Parameters structuring macrophyte communities in rivers and lakes — results from a case study in North-Central Poland. Knowl Manage Aquat Ecosyst 145:08

58. Bytyqi P, Czikkely M, Shala-Abazi A et al (2020) Macrophytes as biological indicators of organic pollution in the Lepenci River Basin in Kosovo. J Freshw Ecol 35:105-121

59. Kaonga CC, Takeda K, Sakugawa H (2016) Concentration and degradation of alternative biocides and an insecticide in surface waters and their major sinks in a semi-enclosed sea, Japan. Chemosphere 145:256-264

60. Lambert SJ, Thomas KV, Davy AJ (2006): Assessment of the risk posed by the antifouling booster biocides Irgarol 1051 and diuron to freshwater macrophytes. Chemosphere 63

61. Mohr S, Berghahn R, Mailahn W et al (2009) Toxic and accumulative potential of the antifouling biocide and TBT successor Irgarol on freshwater macrophytes: a pond mesocosm study. Environ Sci Technol 43:6838-6843

62. Brinke A, Buchinger S, Reifferscheid G et al (2015) Development of a sediment-contact test with rice for the assessment of sediment-bound pollutants. Environ Sci Pollut Res Int 22:12664-12675

63. Tunić $T$, Knežević $V$, Kerkez $Đ$ et al (2015) Some arguments in favor of a Myriophyllum aquaticum growth inhibition test in a water-sediment system as an additional test in risk assessment of herbicides. Environ Toxicol Chem 34:2104-2115

\section{Publisher's Note}

Springer Nature remains neutral with regard to jurisdictional claims in published maps and institutional affiliations.

\section{Submit your manuscript to a SpringerOpen ${ }^{\circ}$ journal and benefit from:}

- Convenient online submission

- Rigorous peer review

- Open access: articles freely available online

- High visibility within the field

- Retaining the copyright to your article

Submit your next manuscript at $\boldsymbol{\nabla}$ springeropen.com 